\title{
A Borehole Thermal Resistance Correlation for a Single Vertical DX U-Tube in Geothermal Energy Application
}

\author{
Ali H. Tarrad \\ Université de Lorraine, CNRS, LEMTA, Nancy, France \\ Email address: \\ alitarrad@yahoo.com \\ To cite this article: \\ Ali H. Tarrad. A Borehole Thermal Resistance Correlation for a Single Vertical DX U-Tube in Geothermal Energy Application. American \\ Journal of Environmental Science and Engineering. Vol. 3, No. 4, 2019, pp. 75-83. doi: 10.11648/j.ajese.20190304.12
}

Received: October 18, 2019; Accepted: November 6, 2019; Published: November 19, 2019

\begin{abstract}
The ground source coupled heat pump is considered as one of the most important technologies utilized in the field of sustainable energy. The borehole thermal resistance has a great impact on the total thermal resistance between the fluid that flows inside the buried U-tube and ground. This issue is related directly to the heat transfer efficiency of the ground part of the heat pump and the effective coefficient of performance of the heat pump system. The capability of the ground heat exchanger to dissipate or absorb energy to or from the ground determines the size and geometry configuration of these heat exchangers. The present research represents a model for the prediction of the borehole thermal resistance of a ground heat exchanger. The U-tube heat source or sink was replaced by a single equivalent concentric tube in the borehole possessing equal thermal resistance as that of the original U-tube heat exchanger. The model was applied for four different U-tube/borehole configurations, the test U-tubes were $(9.52) \mathrm{mm},(12.7) \mathrm{mm},(15.88) \mathrm{mm}$, and (19.05) $\mathrm{mm}$ for a borehole to U-tube diameter ratios range of (3.94) to (7.88). The correlation showed a nonlinear dependency for the equivalent tube diameter and hence the thermal resistance of the filling on the U-tube diameter. It has also shown that for the same U-tube/borehole configuration, increasing of the U-tube legs spacing reduces the thermal resistance and approaching a minimum as the tube legs are located close to the borehole wall. Further, for the same borehole size, the thermal resistance exhibited a decrease as the U-tube size was increased and vice versa. At a borehole size of (75) $\mathrm{mm}$, shank spacing to tube diameter ratio of (2), and a grout thermal conductivity of $(0.78) \mathrm{W} / \mathrm{m} . \mathrm{K}$, the borehole total thermal resistance of the $(9.52) \mathrm{mm}$ U-tube size was higher than that of the (19.05) $\mathrm{mm}$ by (74)\%. The model revealed that the grout thermal conductivity plays an important role in the thermal resistance assessment; the latter showed a decrease as the thermal conductivity increases to the highest test value of $1.9 \mathrm{~W} / \mathrm{m} . \mathrm{K}$. The predicted thermal resistance was compared with other available correlations in the open literature and found to be consistent in the data trend and magnitudes with acceptable margin.
\end{abstract}

Keywords: DX Geothermal System, Borehole Thermal Design, Vertical U-tube, Thermal Resistance Correlation

\section{Introduction}

A ground coupled heat pumps now are utilized widely for the purpose of heating and cooling in residential and commercial buildings. This is due to the fast payback of their installation cost and power consumption cost. Further, such source of energy is cheap, clean and sustainable where the impact on the global warming potential $(G W P)$ is minimized. These heat pumps are usually circulating environment friendly refrigerants which also minimize the impact on the Ozone depletion potential $(O D P)$. Sizing of the ground part of the heat pump is really a complicated issue causes great worries to the designer who looks for optimum design of these units. In addition to the performance of these units; they are required to be economized in a way to reduce the installation and operating costs. Further, these units are sought to obey the national and international prevailing safety regulations of their operation. Modeling of such heat transfer problem is difficult to be handled and represented mathematically. However, a quantitative and qualitative of research work has been accomplished in the field of modeling the (GHE) analytically and experimentally to simplify the problem [1, 2]. The main design objectives were focused on the thermal 
resistance of the grout surrounding the U-tubing and heat transfer rate to or from the ground source. This is because it represents the controller measure to heat transfer process in these heat exchangers.

The analytical models for $(G H E)$ utilize mainly a line heat source and cylinder heat source theory to predict the heat transfer rate between the ground and the heat carrier fluid flowing in the (GHE) [3-6]. Reference [7] proposed a model to calculate the temperature change and the thermal resistance in vertical ground heat exchangers with single Utube installation. They predicted the amount of extractable heat from the U-tube as a function of different fluid mass flow passing through the ground tubing. Reference [8] presented unsteady state model, which couples heat transfer with groundwater seepage for a vertical U-tube ground heat exchanger $(G H E)$. The model examined the influence of underground soil thermal properties, grout materials, inlet water temperature and velocity, and groundwater seepage on heat transfer in the $(G H E)$. They concluded that the effect of thermal-seepage coupling in groundwater can enhance the heat transfer in the $(G H E)$.

A numerical 2-dimensional steady state model to solve the heat conduction problem in a borehole using the finite element analysis by COMSOL Multiphysics software was presented by [9]. The thermal resistance was found to be a geometrical configuration dependent of the U-tube spacing, bore diameter and tube diameter. He concluded that the borehole thermal resistance decreases as shank spacing between U-tube legs of heat exchanger increases. Reference [10] investigated the thermal resistance characteristics of borehole heat exchangers and compared to existing models. They found that all of the available correlations for thermal resistance estimation have similar trend by possess different numerical values depending on their derivative assumptions. They concluded that dimensioning of $(G H E)$ requires knowledge on ground thermal properties, building loads, climate conditions for heating and cooling purposes.

The equivalent diameter of the single tube is a complicated matter especially when dealing with physical presentation of contact surface area, volume of the filling, and conductance of the different factors included in the model. The equivalent diameter of U-tube can be presented in the form of:

$$
d_{e}=\beta d_{o}
$$

Where $(\beta)$ is defined as an equivalency coefficient and is bigger than (1.0). Reference [11] has derived analytically the value of $(\beta)$ for two buried horizontal pipes to be $\sqrt{2}$. For a U-tube heat exchanger, this reveals a constant volume per unit length of the grout for both geometries. Reference [12] reported a scatter for their experimental data for the coefficient value, it was ranged between (1.0) and (1.662) with a mean value of (1.28). Hence, this value was smaller than the $\sqrt{2}$ calculated by [11] and that stated as (1.84) by [13]. Reference [14] presented the grout thermal resistance in the form of:

$$
R_{f=} \frac{\ln \left(\frac{D_{B}}{\sqrt{n} d_{o}}\right)}{2 \pi k_{g}}
$$

In which the equivalent diameter corresponds to:

$$
d_{e}=\sqrt{n} d_{o}
$$

Where $(n)$ is equal to (2) for a single U-tube system. A radial one dimensional model for heat transfer from the fluid and grout was considered. The U-tube pipes were modeled as a single pipe in the center of the bore with an equivalent radius accounted for the same cross sectional area of heat exchange. Reference [15] utilized a steady-state heat transfer simulation based on the cylindrical source model to produce a correlation for the grout resistance for a vertical U-tube ground heat exchanger in the form:

$$
R_{f=} \frac{\ln \left(\frac{D_{B}}{d_{o}} \sqrt{\frac{d_{o}}{S_{p}}}\right)}{2 \pi k_{g}}
$$

This form of expression reveals that the equivalent diameter was expressed as:

$$
d_{e}=\sqrt{S_{p} d_{o}}
$$

The significant impact of the value of $(\beta)$ in (1) is reflects the contribution of both of the surface area of U-tube and grout backfill volume to heat transfer rate of $(G H E)$. Reference [16] developed a correlation for the effective borehole thermal resistance as stated in (6), and was concluded that their correlation predicted the thermal resistance better than other available formulas.

$$
R_{f}=\frac{\left(-1.49 \frac{s_{p}}{D_{B}}+0.656 \ln \left(\frac{D_{B}}{d_{o}}\right)+0.436\right)}{2 \pi k g}
$$

Reference [17] postulated a correlation to predict the borehole thermal resistance for the three configurations of $(G H E)$ pipes, close together, average and along outer wall of the borehole. The expression was formulated as:

$$
R_{f}=\frac{1}{\beta_{0} k_{g}\left(\frac{D_{B}}{d_{o}}\right)^{\beta_{1}}}
$$

The coefficients $\left(\beta_{0}\right)$ and $\left(\beta_{I}\right)$ were stated for three different cases of the U-tube legs as close, average and along the borehole wall. For the case investigated in the present work, average U-tube legs spacing, these values were assigned as (17.44) and (-0.6052) for $\left(\beta_{0}\right)$ and $\left(\beta_{1}\right)$ respectively.

\section{Present Model Derivative}

The transaction of a single U-tube leg from the offset position to the center with equivalent diameter possesses the same shape factor and hence the same thermal resistance, Figure 1. 


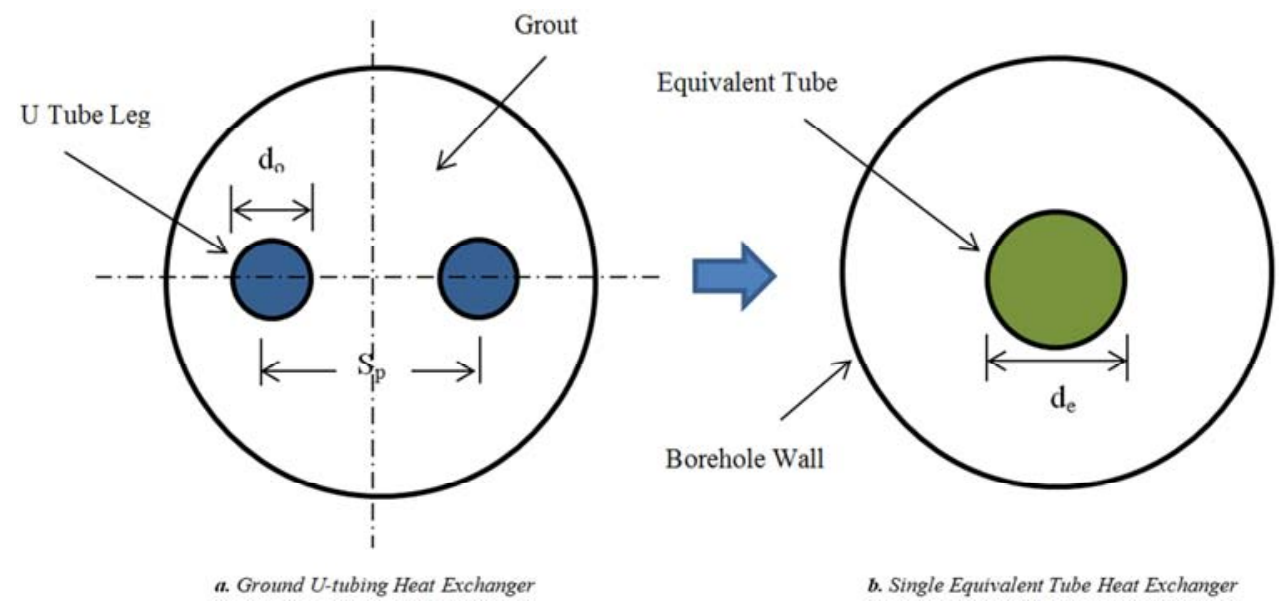

Figure 1. A schematic diagram for the present model presentation.

Let us imagine that the U-tube system, Figure 1a and Figure $2 \mathrm{a}$ is performed as a single offset tube geometry configuration as in Figure $2 b$. The ground conditions when digging deeply in the ground is unchanged and the temperature is undisturbed by the environment temperature fluctuation for the depth range of (50) $\mathrm{m}$ to (100) $\mathrm{m}$ at $(10)^{\circ} \mathrm{C}$. Then such assumption for straighten the U-tube into a single one is justified. Further the tube will be exposed for the same original operating conditions and fluid flow characteristics except the mutual interaction through the shunt between the U-tube legs for the original configuration.

The shunt thermal characteristic vanishes for the case of evaporation or condensation of pure refrigerants, non azeotrop mixtures and azeotrop mixtures of negligible boiling range. In other words, these processes are subject to an isothermal behavior. Hence, the heat transfer rate between the U-tube legs approaches zero, $\Delta T_{\text {ref }}=0$.

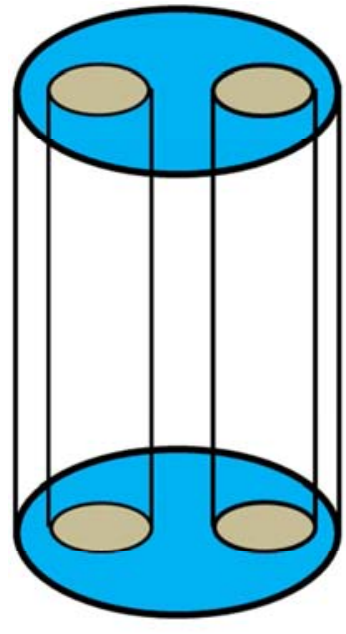

a. Single U-tube

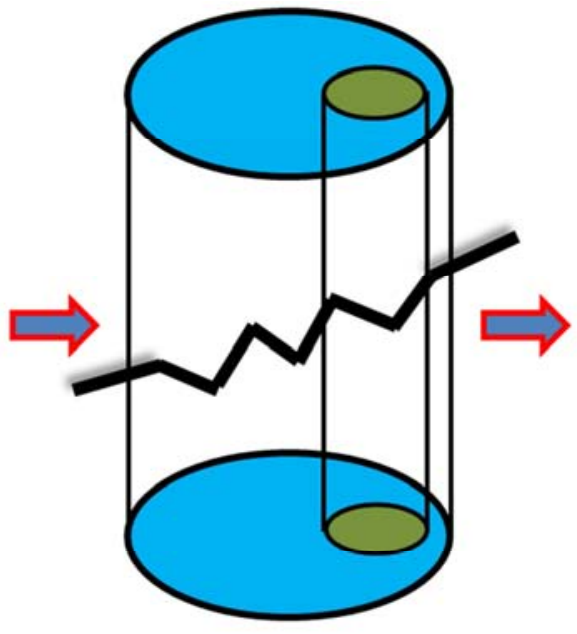

b. A single Offset Tube

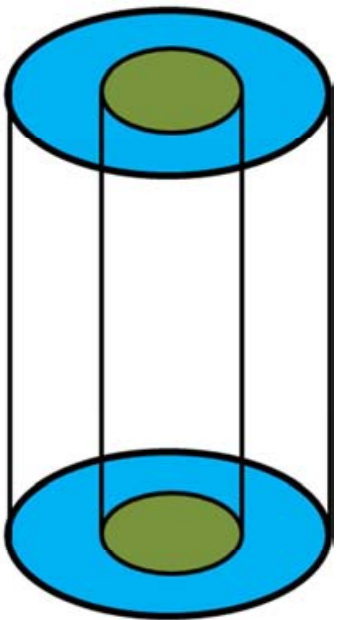

c. Concentric Tube

Figure 2. A borehole presentation with $U$-tube and equivalent tube.

In this context, the single offset tube has a length of double the leg length of the original U-tube. The transformation of the cylindrical heat source from the offset position, Figure $2 b$ to the concentric axis, Figure $2 \mathrm{c}$ is usually accomplished on the expense of thermal resistance. In this work the same thermal resistance between the tube wall and the borehole surface was kept constant by formulating an equivalent diameter of the U-tube legs. The resistance of the offset leg can be expressed according to [18], Figure 2b:

$$
S_{f}=\frac{2 \pi L}{\cosh ^{-1}\left\{\frac{D_{B}^{2}+d_{o}^{2}-S_{p}^{2}}{2 D_{B} d_{o}}\right\}}
$$

The equivalent thermal resistance between the concentric tube wall and the borehole wall, Figure $1 \mathrm{~b}$ and Figure $2 \mathrm{c}$ is expressed from a hollow cylinder experiences a one dimensional conduction heat transfer with length much greater than its radius $\left(L>>r_{B}\right)$, hence:

$$
S_{e}=\frac{2 \pi L}{\ln \left(\frac{D_{B}}{d_{e}}\right)}
$$

Hence these shape factors yield the thermal resistances for both geometrical configurations as: 


$$
\begin{aligned}
& R_{f}=\frac{1}{S_{f} k_{g}} \\
& R_{e}=\frac{1}{S_{e} k_{g}}
\end{aligned}
$$

If we assume that both tube geometries are having the same thermal resistance between the tube wall and borehole wall, then:

$$
R_{f}=R_{e}
$$

Hence

$$
\begin{gathered}
S_{f}=S_{e} \\
\frac{2 \pi L}{\cosh ^{-1}\left\{\frac{D_{B}^{2}+d_{o}^{2}-S_{p}^{2}}{2 D_{B} d_{o}}\right\}}=\frac{2 \pi L}{\ln \left(\frac{D_{B}}{d_{e}}\right)}
\end{gathered}
$$

This relation gives:

$$
\ln \left(\frac{D_{B}}{d_{e}}\right)=\cosh ^{-1}\left\{\frac{D_{B}^{2}+d_{o}^{2}-S_{p}^{2}}{2 D_{B} d_{o}}\right\}
$$

The general expression for the inverse hyperbolic relation is corresponding to:

$$
\cosh ^{-1} x=\ln \left\{x+\sqrt{x^{2}-1}\right\}
$$

In this mathematical expression:

$$
x=\frac{D_{B}^{2}+d_{o}^{2}-S_{p}^{2}}{2 D_{B} d_{o}}
$$

Solution of (15) gives the following expression for the equivalent diameter:

$$
d_{e}=\frac{D_{B}}{\left(x+\sqrt{x^{2}-1}\right)}
$$

This expression shows the interaction between all geometry parameters of the borehole on the transformation of the suggested equivalent diameter of the U-tube configuration. Once the equivalent diameter was obtained then the thermal resistance of the grout for the equivalent geometry is calculated from $(9 \& 11)$. The equivalent diameter possesses the same convection resistance of the fluid flowing inside the original tube and its conduction resistance through the tube wall. Hence, the borehole thermal resistance is expressed as:

$$
\begin{gathered}
R_{B}=R_{f}+R_{p} \\
R_{p}=\frac{1}{\pi d_{i} h}+\frac{\ln \left(\frac{d_{o}}{d_{i}}\right)}{2 \pi k_{p}} \\
R_{f}=\frac{\ln \left(\frac{D_{B}}{d_{e}}\right)}{2 \pi k_{g}}
\end{gathered}
$$

The thermal resistance of the refrigerant flowing inside the tube is normally corresponding to a negligible magnitude for condensation, evaporation and turbulent flow where the heat transfer coefficients are so high. Further, in $(D X)$ heat exchangers, copper tubing is usually implemented for the Utube metal which possesses a high thermal conductivity of about (400) W/m.K with a negligible thermal resistance. Therefore (20) reveals very low values of $\left(R_{p}\right)$ for a $(D X)$ evaporators and condensers in comparison with grout and ground resistances. In this work, it has been found that pipe resistance fell within the range of $(2-5) \%$ of the total borehole thermal resistance for the investigated grout thermal conductivity range.

\section{Ground and Total Resistance}

The thermal resistance of the ground is important for the calculation of the heat load absorbed or rejected by the Utube heat exchanger and its dimensional size including diameter, length and other requirements. The analytical model presented by [7] showed that the ground factor is a time dependent measure. They have concluded that a steady state operation was obtained after (1) year operation with a value of $(0.053) \mathrm{m} . \mathrm{K} / \mathrm{W}$ for ground thermal resistance calculated at a ground thermal conductivity of (2.42) W/m.K. Hence, it was decided to implement this value at the present work. Therefore the total thermal resistance per unit length is estimated by:

$$
R_{t}=\frac{\ln \left(\frac{D_{B}}{d_{e}}\right)}{2 \pi k_{g}}+R_{p}++R_{s}
$$

\section{Results and Discussion}

The present model was verified by the comparison with other published correlation in the field of borehole thermal resistance calculation of a U-tube ground heat exchanger such as [14-17].

\subsection{Effect of Grout Thermal Conductivity}

The grout specific thermal resistance at various grout thermal conductivity is compared in Figure 3 for three different tube wall factors. The trend of all of the tested correlation is similar with different numerical values. The expression of [14] showed the highest specific thermal resistance among other correlation and is closer to the present predicted values for $W F$ of (14.29) and (15.63), Figures 3a and $3 b$.

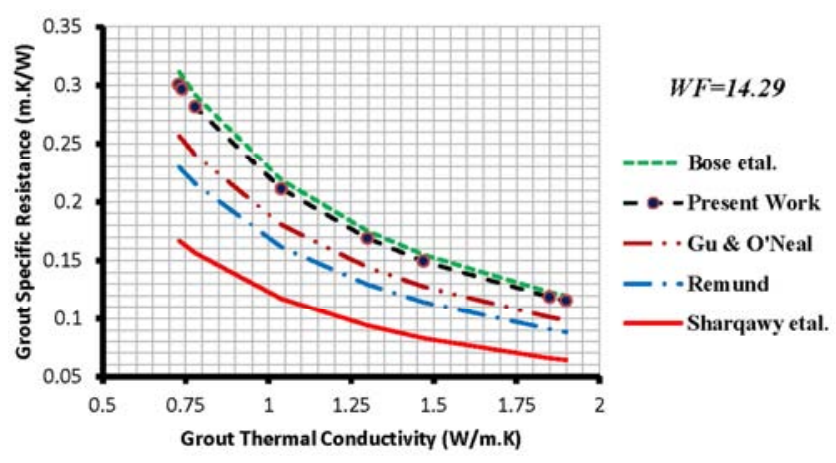

a. Comparison at $\mathrm{WF}=14.29$ 


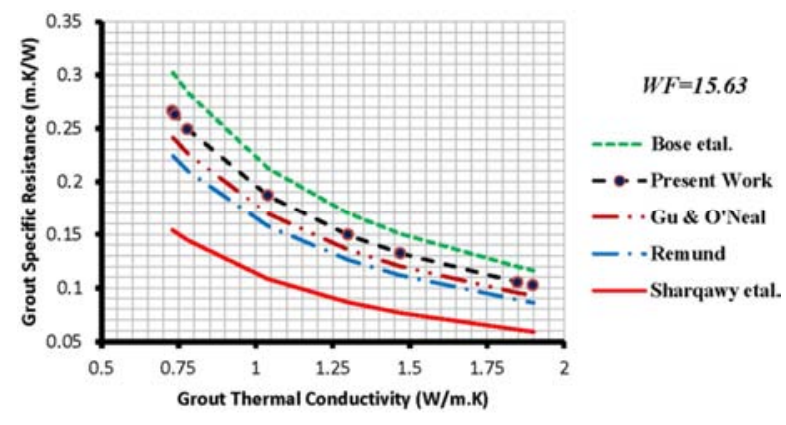

b. Comparison at $\mathrm{WF}=15.63$

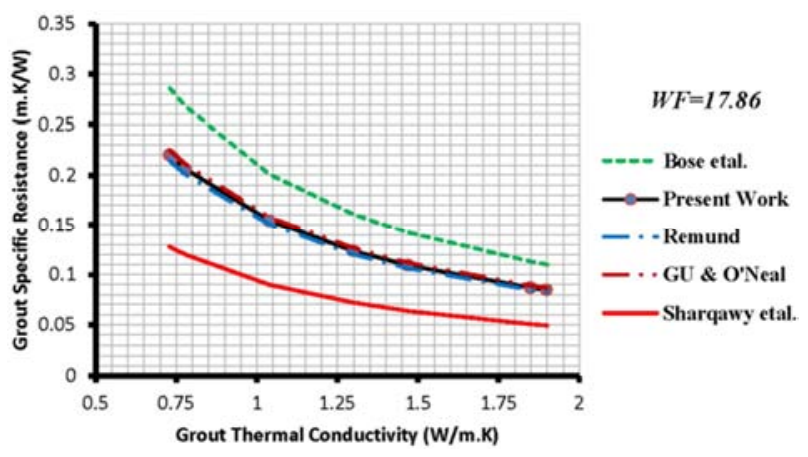

c. Comparison at $\mathrm{WF}=17.86$

Figure 3. Comparison of the present work grout specific resistance with existing models.

Increasing of tube diameter results in an increase of the equivalent diameter and lowers the thermal resistance of the grout. The coefficient of (1) depends on all of the geometrical parameters but not on the tube spacing alone as presented by [15] or a constant value as suggested by [14].

Reference [16] showed that the thermal resistance of the borehole depends on $\left(D_{B}\right),\left(S_{p}\right)$ and $\left(d_{o}\right)$ in addition to the thermal conductivity of the filling. However, their correlation predicted the lowest thermal resistance among other tested models, Figure 3. At $W F$ of (17.86) the present work exhibited closer values to those of $[15,17]$ correlations as illustrated in Figure 3c. This is mainly due to the dependence of the present relation on the geometrical values, borehole diameter, U-tube spacing and tube outside diameter which are interact to predict the equivalent diameter of the present work.

The equivalent diameters predicted by different correlations are shown in Table 1 for the purpose of comparison. These correlations share the same technique of replacing the U-tube geometry to a single concentric equivalent tube which possesses the same characteristic operating conditions. It is obvious that these correlations reveal different values of equivalent diameter depending on their $(\beta)$ value nevertheless they produced the same trend of data. The predicted data has proved that the equivalent diameter is a function of geometrical parameters related to the borehole design. The coefficient $(\beta)$ revealed a variable value for different sizes of the U-tube and borehole dimensions.

The present work postulated a value of $(\beta)$ to vary between (1.49) and (1.93) with a mean value of (1.7) for the examined geometries. Reference [12] has also reported a scatter for their experimental data for the coefficient value ranged between (1.0) and (1.662). The predicted value by the present work is close enough to their postulated values of (1.662).

Table 1. Detailed design dimensions for selected borehole geometry configurations deduced from the present model.

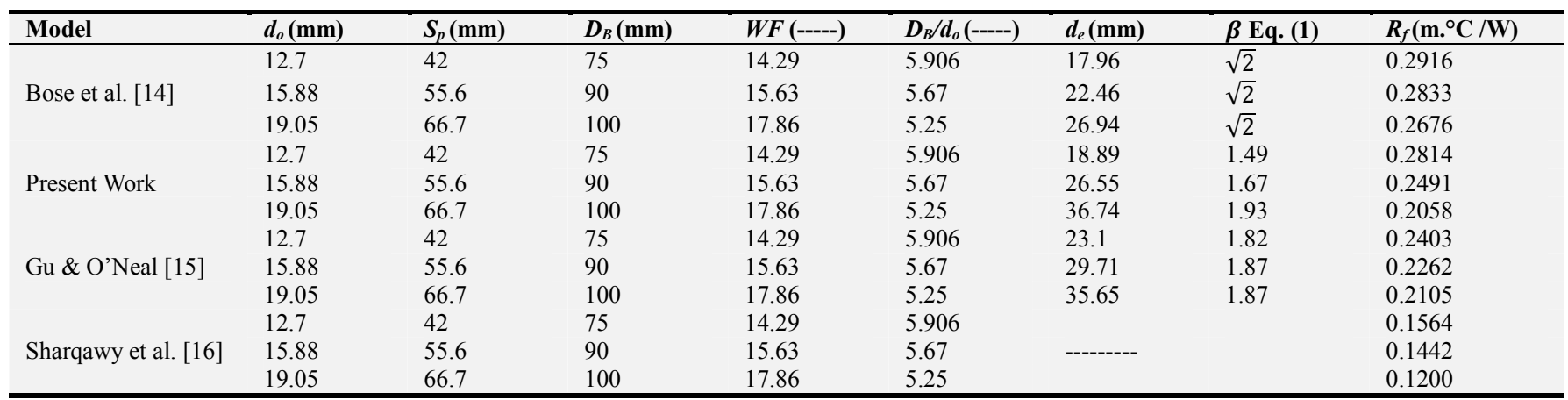

The correlation of [15] showed a value of $(\beta)$ in the range of (1.82-1.87) whereas [14] used a smaller value than other correlations to be (1.41). The outcome of this discrepancy in the equivalent diameter assessment is reflected directly on the borehole design criterion and thermal resistance of the ground heat exchanger design. The total thermal resistance that exists between the flowing refrigerant inside the tube and the extending ground region to infinity is affected directly by the method of its assessment. Hence, the thermal design of those heat exchangers to predict the proper size to attend a specified heat transfer load.

The specific total thermal resistance between the tube and ground is compared in Figure 4 with other investigators. The effect of tube size is obvious for the prediction of the total thermal resistance of the borehole. As it increases, the thermal resistance

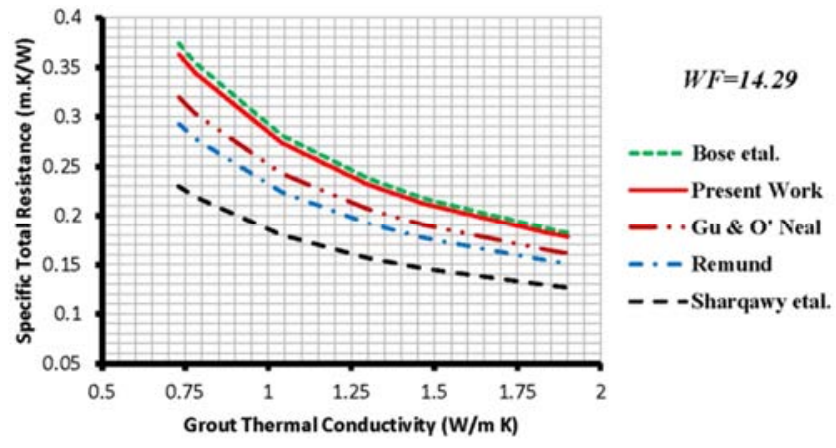
declines sharply as detected by the present and [15] correlations.

a. Comparison at $\mathrm{WF}=14.29$ 


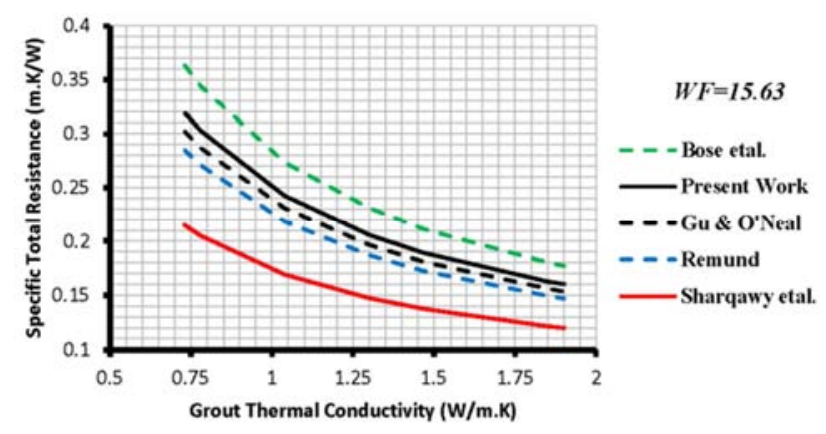

b. Comparison at $\mathrm{WF}=15.63$

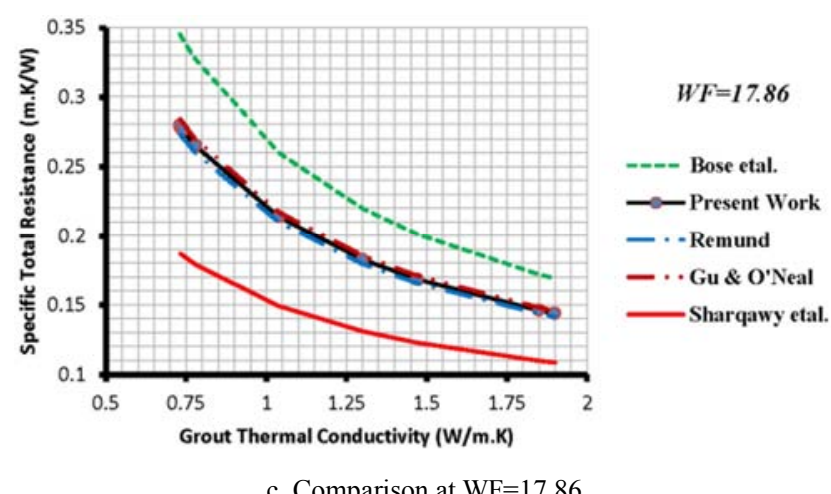

Figure 4. Comparison of the present work borehole resistance with existing models for different borehole configurations, Table 1.

The present model predicted a moderate total thermal resistance and is accommodated at the mid-distance between the predicted values of [16] and [14] for $W F$ of (17.86), the biggest tested tube diameter. As the U-tube diameter increases, the present model predicted thermal resistance moves to be closer to those of [15] and [17]. This is mainly because the present work and [15] models took into account the effect of U-tube legs spacing and its diameter when estimating the concentric equivalent tube diameter.

\subsection{Effect of Tube Spacing at Fixed $\left(D_{B} / d_{o}\right)$}

Table 2 shows the characteristics of the borehole geometries assigned for this purpose. A borehole diameter and tube outside diameter were chosen as (75) $\mathrm{mm}$ and (12.7) $\mathrm{mm}$ respectively. Equation (18) shows that the equivalent diameter is a function of $\left(D_{B}\right),\left(d_{o}\right)$ and $\left(S_{p}\right)$. Hence for this category when $\left(D_{B}\right)$ and $\left(d_{o}\right)$ were chosen as fixed parameters then in effect we are examining the effects of $\left(S_{p}\right)$ and $\left(D_{B} / S_{p}\right)$ on the thermal resistance.

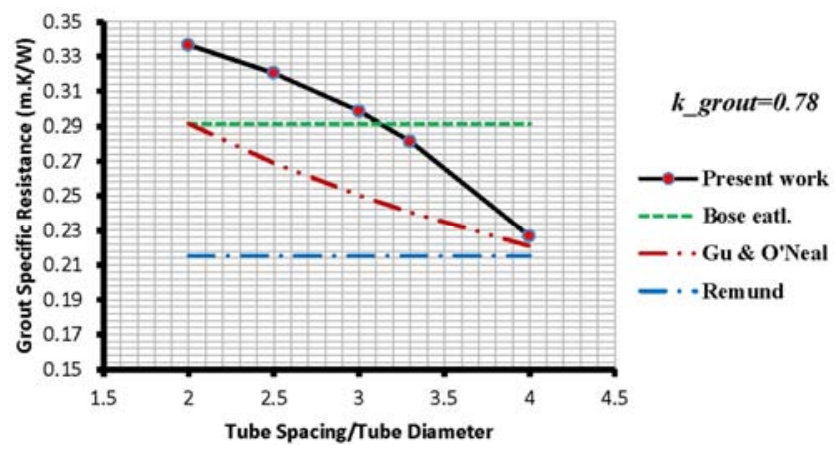

Figure 5. Predicted grout specific thermal resistance variation with $\left(S_{p} / d_{o}\right)$ at fixed $\left(D_{B}\right)$ and $\left(d_{o}\right)$.

\begin{tabular}{|c|c|c|c|c|c|c|}
\hline$d_{0}(\mathrm{~mm})$ & $\mathrm{S}_{\mathrm{p}}(\mathrm{mm})$ & $S_{p} / d_{0}(---)$ & $D_{B}(\mathrm{~mm})$ & $\mathrm{D}_{\mathrm{B}} / \mathrm{S}_{\mathrm{p}}(---)$ & $d_{e}(m m)$ & $\beta(---)$ \\
\hline 12.7 & 25.4 & 2 & 75 & 3.937 & 14.408 & 1.13 \\
\hline 12.7 & 31.75 & 2.5 & 75 & 2.36 & 15.597 & 1.23 \\
\hline 12.7 & 38.1 & 3 & 75 & 1.97 & 17.364 & 1.37 \\
\hline 12.7 & 41.91 & 3.3 & 75 & 1.79 & 18.887 & 1.49 \\
\hline 12.7 & 50.8 & 4 & 75 & 1.48 & 24.702 & 1.95 \\
\hline
\end{tabular}

Figure 5 was produced to illustrate the effect of the tube spacing on the grout specific thermal resistance and hence on the total value which determines the ground heat exchanger size.

The results for this borehole dimensions were compared between different correlations under the same geometry configuration. The correlations built by $[14,17]$ didn't show any response to the geometry dimension variation, therefore they revealed constant values as straight horizontal lines as illustrated in Figure 5. The present correlation exhibited a good interaction with the geometry configuration and physical dimension of the borehole size. The thermal resistance of the grout and hence the borehole is a strong function of the spacing, U-tube size and to some extent to the borehole diameter as confirmed by $[15,16]$ and present work as depicted in Figure 4.

The correlation of [15] and the present work showed the response of the thermal resistance to the tube spacing and diameter. As the tube spacing increases, the grout thermal resistance, borehole resistance and hence the total borehole resistance decrease. Their values approaching a minimum as the tubes reach closer to the borehole boundary, in this category the $\left(S_{p} / d_{o}\right)$ equal to (4). This phenomenon was also confirmed by [17] for the case where the U-tube legs situated along the borehole surface. He found the minimum thermal resistance would be attained under these conditions.

The predicted grout specific resistance by [14] was higher than that of [17] by (35.4)\% and it was higher by $(0-32) \%$ than that of [15] depending on the $\left(S_{p} / d_{o}\right)$. Reference [15] expression produced values for the thermal resistance bounded by the $[14,17]$ values showing a limited variation with geometrical configuration variation. The curves of the predicted thermal resistance of [14] and [15] are intersecting at $\left(S_{p} / d_{o}\right)$ corresponds to (2). Figure 6 shows the variation of the borehole total thermal resistance with geometry factor $\left(S_{p} / D_{B}\right)$ for $W F$ of (14.29) and borehole diameter of (75) mm, Table 2. 


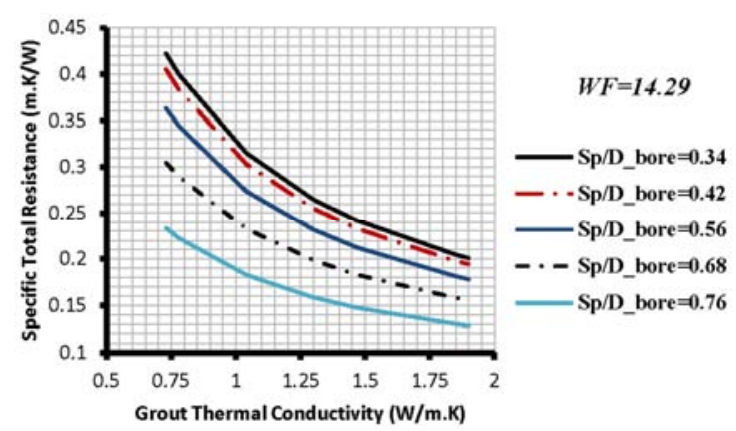

Figure 6. Predicted grout specific thermal resistance variation with $\left(S_{p}\right)$ at fixed $\left(D_{B}\right)$ and $\left(d_{o}\right)$.

It is obvious that increasing the tube spacing is always accompanied by a decrease in the grout specific thermal resistance for both correlations of [15] and that of the present work. The earlier correlation exhibited almost a linear variation with tube spacing of the U-tube legs whereas the present correlation showed a nonlinear trend with the tube spacing. The wider the tube spacing the lower thermal resistance is to be expected for a fixed borehole diameter and vice versa. This is due to the fact that increasing of the distance between the U-tube legs produces a bigger single equivalent tube diameter, Table 2 , and hence reduces the grout thermal resistance. The closer tubes are undesirable due to the high thermal resistance to heat flow from and to outside zone of the borehole. This phenomenon was also confirmed by [17] work for close tubes of the U-tube assembly. Reference [9] has also concluded in his analytical work that increasing the shank distance between the U-tube legs reduces the thermal resistance of the borehole.

It seems that there is a sort of optimum value for the ratio of tube spacing to outside tube diameter where the design should be selected around that point Figures 5 and 6. Considering a big ratio value will reduce the thermal resistance. But that will be on the expenses of mechanical design requirement of the borehole geometry. The design should always keep the U-tube legs away from the borehole surface which is a risky position for air penetration and increases the porosity of the medium in case of a grout preparation failure.

\subsection{Effect of Tube Diameter at Fixed $\left(S_{p} / d_{o}\right)$}

The response of the present correlation to the effect of different geometrical parameters was studied for the case where a fixed value of $\left(S_{p} / d_{o}\right)$ was chosen for different tube diameters. In other words, for the case where different values of $\left(D_{B} / d_{p}\right)$ were selected at fixed borehole diameter as illustrated in Table 3.

Table 3. Characteristics of test geometries for fixed $\left(S_{p} / d_{o}\right)$ and $\left(D_{B}\right)$.

\begin{tabular}{lllllll}
\hline $\mathbf{d}_{\mathbf{0}}(\mathbf{m m})$ & $\mathbf{D}_{\mathbf{B}}(\mathbf{m m})$ & $\mathbf{S}_{\mathbf{p}} / \mathbf{d}_{\mathbf{0}} \mathbf{( - - - - )}$ & $\mathbf{S}_{\mathbf{p}}(\mathbf{m m})$ & $\mathbf{D}_{\mathbf{B}} / \mathbf{d}_{\mathbf{p}}(----)$ & $\mathbf{d}_{\mathbf{e}}(\mathbf{m m})$ & $\boldsymbol{\beta}(---)$ \\
\hline 9.52 & 75 & 2 & 19.04 & 7.88 & 10.194 & 1.07 \\
12.7 & 75 & 2 & 25.4 & 5.91 & 14.408 & 1.13 \\
15.88 & 75 & 2 & 31.75 & 4.724 & 19.592 & 1.23 \\
19.05 & 75 & 2 & 3.937 & 26.591 & 1.40 \\
\hline
\end{tabular}

Figure 7 depicts the response of the present correlation to the effect of the ratio defined by $\left(D_{B} / d_{o}\right)$ and its comparison with other available expressions derived by [14, 15, 17]. It is clear that all of these correlations showed the same trend of the predicted grout and total thermal resistance with $\left(D_{B} / d_{o}\right)$. The general behavior of these curves was also confirmed by the work of [9] in his numerical analysis and the prediction of [19]. The trend of the prediction emphasized that increasing of $\left(D_{B} / d_{o}\right)$ increases the grout thermal resistance and vice versa.

Noting that the data showed in Table 3 and Figure 7 is presented for the case where the borehole diameter is fixed and changing the U-tube diameter. Therefore, increasing the ratio of $\left(D_{B} / d_{o}\right)$ refers to the reduction of the tube diameter and vice versa. Hence its value leads to a smaller equivalent diameter of the single tube which this in turn increases the thermal resistance of the grout. The present work showed higher resistance than other correlations due to the reduction in the predicted equivalent diameter as stated by (18). This leads to the case where the single tube is exposed to a higher thermal resistance than that of the bigger tube diameters due to the increase of grout layer around the single equivalent tube.

Figure 7 shows that both of the $[14,15]$ correlations predicted the same values of the grout and total thermal resistances. This is due to the fact that when $\left(S_{p} / d_{o}\right)$ equal to (2), then both correlations predicted the same equivalent diameter of the U-tube and hence equal resistances. Reference [17] expression predicted the lowest values of thermal resistance than other correlations for the whole tested range.

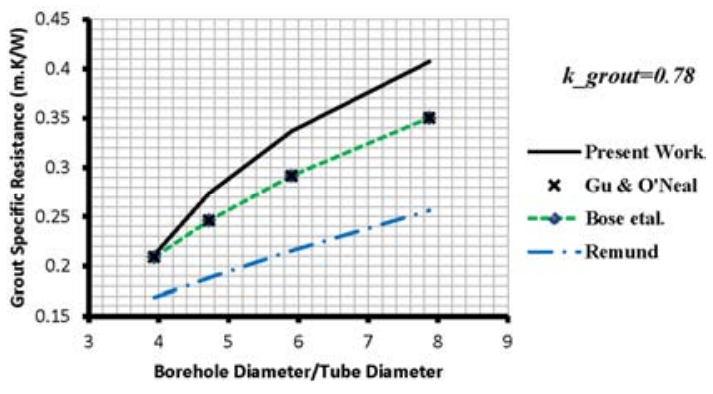

a. Grout specific thermal resistance variation

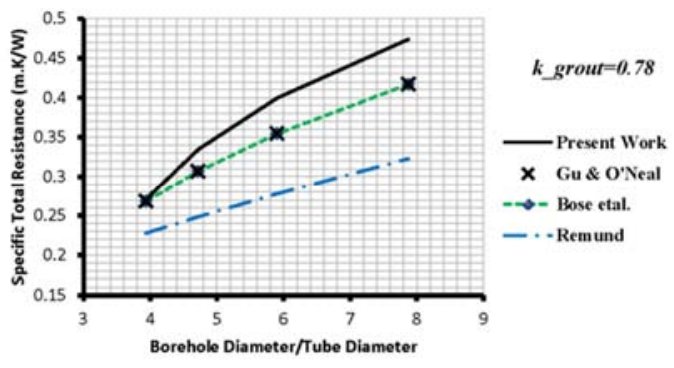

b. Total specific thermal resistance variation

Figure 7. Predicted grout specific and total thermal resistances variation with $\left(D_{B} / d_{o}\right)$ at fixed $\left(S_{p} / d_{o}\right)$ and $\left(D_{B}\right)$. 


\section{Conclusions}

The thermal resistance of the borehole for a ground heat exchanger is a complex criterion of the borehole configuration and its size. A correlation for the thermal resistance of the borehole was developed by replacing the Utube by an equivalent concentric single tube at the borehole. The predicted equivalent diameter is shown to be a strong function of the geometry configuration of the borehole with a nonlinear response to the borehole configuration. The equivalency coefficient as presented in (1) was shown to be a geometry configuration dependent but not a constant value. At $\left(D_{B}\right)$ of $(75) \mathrm{mm}$ and $\left(d_{o}\right)$ of $(12.7) \mathrm{mm}$, the equivalency coefficient $(\beta)$ was increased from (1.3) to (1.95) when the $\left(S_{p} / d_{o}\right)$ was shifted from (2) to (4). The coefficient $(\beta)$ exhibited a lower increase when the tube diameter was increased from $(9.52)$ to $(19.05) \mathrm{mm}$ at $\left(D_{B}\right)$ and $\left(S_{p} / d_{o}\right)$ of (75) $\mathrm{mm}$ and (2) respectively. The $(\beta)$ values for $(9.52) \mathrm{mm}$ and $(19.05) \mathrm{mm}$ tube diameter were only (1.07) and (1.4) respectively. The predicted thermal resistance showed a decrease as $\left(S_{p} / d_{o}\right)$ or $\left(S_{p}\right)$ increases for fixed $\left(D_{b} / d_{o}\right)$ due to the increase of $\left(d_{e}\right)$. At a borehole size of (75) mm, $\left(d_{o}\right)$ of (12.7) $\mathrm{mm}$, and a grout thermal conductivity of $(0.78)$ $\mathrm{W} / \mathrm{m} . \mathrm{K}$, the grout thermal resistance exhibited a reduction by (32)\% when the $\left(S_{p} / d_{o}\right)$ was increased from (2) to (4). The predicted thermal resistance showed an increase as the $\left(D_{b} / d_{o}\right)$ increases for fixed $\left(D_{b}\right)$ and $\left(S_{p} / d_{o}\right)$. At a borehole size of (75) mm, $\left(S_{p} / d_{o}\right)$ of (2) and a grout thermal conductivity of $(0.78) \mathrm{W} / \mathrm{m} . \mathrm{K}$, the borehole total thermal resistance of the (9.5) $\mathrm{mm}$ U-tube size was higher than that of the (19.05) $\mathrm{mm}$ by $(74) \%$.

\section{Nomenclatures}

Parameter
$d$
$D$
$h$
$k$
$L$
$n$
$R$
$S$
$S_{p}$
$t$
$\Delta T$
$W F$

Definitions

Tube diameter $(\mathrm{m})$

Borehole diameter $(\mathrm{m})$

Heat transfer coefficient $\left(\mathrm{W} / \mathrm{m}^{2} . \mathrm{K}\right)$

Thermal conductivity (W/m.K)

Length ( $\mathrm{m}$ )

Number of tubes inside a borehole

Thermal resistance per unit length (m.K/W)

Geometrical shape factor $(\mathrm{m})$

Tube spacing (m)

Tube thickness $(\mathrm{m})$

Temperature difference $\left({ }^{\circ} \mathrm{C}\right)$

Wall factor defined as $\left(d_{0} / t\right)$

\section{Subscriptions}

$\begin{array}{ll}\text { B } & \text { Borehole } \\ \text { e } & \text { Equivalent } \\ \mathrm{f} & \text { Filling or grout } \\ \mathrm{g} & \text { Grout } \\ \mathrm{i} & \text { Inside } \\ \mathrm{o} & \text { outside } \\ \mathrm{p} & \text { Pipe }\end{array}$

$\begin{array}{ll}\text { ref } & \text { Refrigerant } \\ \mathrm{s} & \text { Soil or ground } \\ \mathrm{t} & \text { Total }\end{array}$

\section{Greek Letters}

$\begin{array}{ll}\beta & \text { Equivalency coefficient defined in (1) } \\ \beta_{0} & \text { Coefficient in (7) } \\ \beta_{1} & \text { Coefficient in (7) }\end{array}$

\section{Abbreviations}

$\begin{array}{ll}\text { GHE } & \text { Ground Heat Exchanger } \\ \text { GWP } & \text { Global Warming Potential } \\ \text { ODP } & \text { Ozone Depletion Potential }\end{array}$

\section{References}

[1] S. Kavanaugh, "Simulation and experimental verification of vertical ground coupled heat pump systems", $\mathrm{PhD}$. Thesis, Oklahoma State University, USA, 1985.

[2] H. Zeng, N. Diao, Z. Z. Fang Z., "Heat transfer analysis of boreholes in vertical ground heat exchangers", International journal of Heat and Mass Transfer 46, 44674481, 2003.

[3] N. Muttil, K. W. Chau, "Neural network and genetic programming for modeling coastal algal blooms. Int. J. Environ. Pollution, 28, 223-238, 2006.

[4] L. R., Ingersoll, O. J. Zobel, A. C. Ingersoll, "Heat conduction with engineering and Geological application", McGraw Hill: New York, 1948.

[5] H. S. Carslaw, J. C. Jaeger, "Conduction of heat in solids", 2nd ed.; Oxford University Press: London, 1959.

[6] L. R. Ingersoll, O. J. Zobel, A. C. Ingersoll, "Heat conduction with engineering, Geological and other applications", revised edition; University of Wisconsin Press: Madison, 1954.

[7] L. Garbai, S. Méhes, "Heat capacity of vertical ground heat exchangers with single U-tube installation in the function of time", Wseas Transactions on Heat and Mass Transfer, 3 (3), 177-186, July 2008.

[8] S. Chen, J. Mao, X. Han, C. Li, L. Liu, "Numerical analysis of the factors influencing a vertical U-Tube ground heat exchanger", Sustainability, 8, 1-12, 2016, doi: 10.3390/su8090882.

[9] Z. Sagia, "Borehole resistance and heat conduction around vertical ground heat exchangers", The Open Chemical Engineering Journal, 6, 32-40, 2012.

[10] Ö. Kizilkan, I. Dincer, "Evaluation of thermal characteristics of a borehole thermal energy storage system", Proceeding of the Sixth International Exergy, Energy and Environment Symposium (IEEES-6), 1-4 July 2013.

[11] J. Claesson, A. Dunand, "Heat extraction from the ground by horizontal pipes- A mathematical Analysis", Document D1, Swedish Council for Building Research, Stockholm, 1983. 
[12] V. C. Mei, V. D. Baxter, "Performance of a ground coupled heat pump with multiple dissimilar U-tube coils in series. ASHRAE Transactions, 92 (2A), 30-42, 1986.

[13] R. D. Fischer, G. H. Stickford., "Technical and economic feasibility of horizontal, multiple shallow-well and deep-well ground coupling, ORNUSub/80-78001 3\&06. Oak Ridge, Tenn.: Oak Ridge National Laboratory, 1983.

[14] J. E. Bose, J. D. Parker, F. C. McQuiston, "Design/Data manual for closed-loop ground-coupled heat pump systems", American Society of Heating, Refrigeration and Air Conditioning Engineers (ASHRAE): Atlanta, 1985.

[15] Y. Gu, D. L. O’Neal, “Development of an Equivalent Diameter
Expression for Vertical U-Tubes Used in Ground-Coupled Heat Pumps. ASHRAE Transactions, 104 (2), 1-9, 1998.

[16] H. M. Sharqawy, E. M. Mokheimer, H. M. Badr, "Effective pipe-to-borehole thermal resistance for vertical ground heat exchangers", Geothermics, 38, 271-277, 2009.

[17] C. P. Remund, "Borehole thermal resistance: laboratory and field studies", ASHRAE Trans., 105, 439-445, 1999.

[18] J. P. Holman, "Heat Transfer", $10^{\text {th }}$ edition, McGraw-Hill, chapter 3, 83-86, 2010.

[19] J. A. Shonder, J. V. Beck, "Determining effective soil formation thermal properties from field data using a parameter estimation technique", ASHRAE Trans., 105, 458-466, 1999. 